\title{
Upper gastrointestinal tract involvement of Crohn disease: clinical implications in children and adolescents
}

Eun Sil Kim, MD, MS, Mi Jin Kim, MD, PhD

Department of Pediatrics, Samsung Medical Center, Sungkyunkwan University School of Medicine, Seoul, Korea

Crohn disease (CD) is a multifactorial inflammatory disorder that can affect all segments of the gastrointestinal (GI) tract but typically involves the ileum and/or colon. To assess patient prognosis and choose appropriate treatment, it is necessary to accurately evaluate the factors influencing poor outcomes, including disease phenotype. Pediatric $\mathrm{CD}$ involving the upper GI (UGI) tract has become increasingly recognized with the introduction of routine upper endoscopy with biopsies for all patients and the increased availability of accurate small bowel evaluations. Most clinical manifestations are mild and nonspecific; however, UGI involvement should not be overlooked since it can cause serious complications. Although controversy persists about the definition of upper GI involvement, aphthoid ulcers, longitudinal ulcers, a bamboo jointlike appearance, stenosis, and fistula are endoscopic findings suggestive of $\mathrm{CD}$. In addition, the primary histological findings, such as focally enhanced gastritis and noncaseating granulomas, are highly suggestive of CD. The association between UGI involvement and poor prognosis of $\mathrm{CD}$ remains controversial. However, the unstandardized definition and absence of a validated tool for evaluating disease severity complicate the objective assessment of UGI involvement in CD. Therefore, more prospective studies are needed to provide further insight into the standardized assessment of UGI involvement and longterm prognosis of $\mathrm{CD}$. Our review summarizes the findings to date in the literature as well as UGI involvement in CD and its clinical implications.

Key words: Crohn disease, Upper gastrointestinal tract, Oral cavity, Gastroduodenal disease, Small bowel

\section{Key message}

Clinical manifestations of upper gastrointestinal (UGI) tract involvement in Crohn disease (CD) are common but often clinically underestimated.

Diagnosing CD by confirming inflammation of the UGI tract histologically is challenging because macroscopic and microscopic findings overlap with those of other diseases.
Ongoing efforts are needed to enable a standardized assessment of UGI CD in the future.

\section{Introduction}

Crohn disease $(\mathrm{CD})$ is a multifactorial and inflammatory disorder of the gastrointestinal (GI) tract characterized by a relapsing-remitting clinical course with the progressive accumulation of bowel damage. ${ }^{1)}$ Approximately $25 \%$ of patients with $\mathrm{CD}$ are diagnosed during childhood and adolescence. ${ }^{2)}$ The incidence and prevalence of CD have increased remarkably, indicating its emergence as a global disease. ${ }^{3)}$ Especially in pediatric patients, the incidence of $\mathrm{CD}$ increased from 5.2 per 100,000 (95\% confidence interval [CI], 4.3-6.2) in 1994 to $7.9 \%$ per 100,000 (95\% CI, 6.9-9.0) in $2009(P<0.0001){ }^{4}{ }^{4}$ Similarly, the incidence of pediatric $\mathrm{CD}$ has increased exponentially in South Korea. ${ }^{5)}$

To assess the prognosis and implement appropriate treatment for patients with $\mathrm{CD}$, it is necessary to accurately evaluate the factors influencing poor outcomes. The factors affecting the disease course of $C D$ are disease phenotypes including young age at diagnosis, early stricturing (B2) and/or penetrating (B3) disease behavior, perianal disease, and upper GI (UGI) involvement with/without extensive small bowel disease. ${ }^{6-8)}$ To facilitate clear disease phenotyping, inflammatory bowel disease (IBD) experts categorize $\mathrm{CD}$ into 4 phenotypes according to disease location: ileal (L1), colonic (L2), ileocolic (L3), and UGI (L4) disease, that is, proximal CD, according to Montreal classification for adults and Paris classification for pediatric patients. ${ }^{910)}$ Pediatric CD involving the UGI tract has become increasingly recognized by the introduction of routine upper endoscopy with biopsies for all patients being evaluated for CD. ${ }^{11)}$ The recently increased availability of accurate small bowel evaluations such as capsule endoscopy and magnetic resonance enterography (MRE) as well as computed tomography (CT) has led to increased reporting of the UGI involvement of CD. ${ }^{12)}$

It is generally known that UGI involvement is more prevalent

Corresponding author: Mi Jin Kim, MD, PhD, Department of Pediatrics, Samsung Medical Center, Sungkyunkwan University School of Medicine, 81 Irwon-ro, Gangnam-gu, Seoul 06351, Korea 


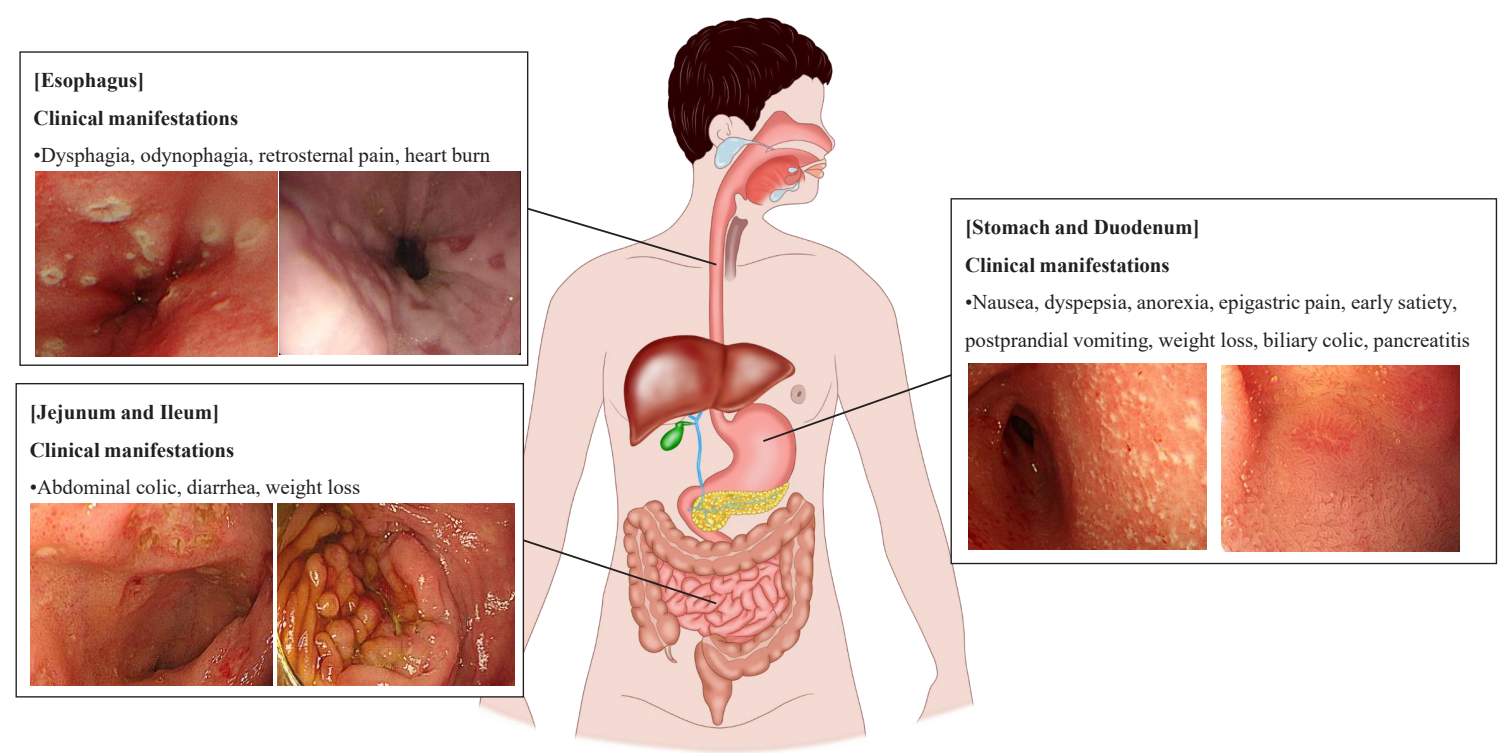

Graphical abstract. Summary of upper gastrointestinal involvement of Crohn disease

in pediatric than in adult $\mathrm{CD}$ patients and that a younger age at diagnosis in both adults and children is associated with UGI involvement. ${ }^{13)}$ In addition, a male sex predominance is reported at a ratio of 1.2:1 for UGI involvement among patients with $\mathrm{CD} .{ }^{14)}$ The mean age of pediatric patients diagnosed with proximal CD is 10.9 years compared with 12.6 years for those diagnosed with distal $C D .{ }^{15}$ ) For adult patients with $\mathrm{CD}$, the mean age at diagnosis is 21.2 years for proximal disease versus 25.4 years for distal disease. ${ }^{16}$ This review discusses the UGI involvement of $\mathrm{CD}$, one of its phenotypes that is known to affect prognosis.

\section{Definitions of oral and UGI involvement of CD}

Oral involvement is frequently reported in $\mathrm{CD}$ and is usually called oral CD (OCD). ${ }^{17)}$ The definition of OCD is highly variable, including lip swelling, cobble stoning of the buccal mucosa, ulceration and fissuring of the oral cavity, and/or gingival swelling. ${ }^{18)}$ Regardless, histological confirmation is required in all cases of OCD.

Although controversy persists about the definition of UGI involvement in $\mathrm{CD}$, it is generally defined as mucosal ulcerations of the UGI tract on endoscopy or bowel wall thickening on radiography. ${ }^{10)}$ The presence of mucosal erythema and/or granularity is insufficient to be considered evidence of UGI involvement. The generally accepted diagnostic criteria for UGI involvement of CD were proposed by Nugent and Roy: (1) characteristic histology with noncaseating granuloma, with or without obvious $\mathrm{CD}$ elsewhere in the intestinal tract in the absence of a systemic granulomatous disorder, or (2) documented CD elsewhere in the intestinal tract and radiological or endoscopic findings of diffuse inflammation in the UGI tract consistent with CD. ${ }^{19)}$
The UGI involvement of CD is categorized by the Montreal and Paris classifications as an L4 phenotype, and L4 can be added to L1-3 classification when concomitant UGI disease is present. ${ }^{9,10)}$ The L4 phenotype is defined as upper disease from the esophagus to the proximal $2 / 3$ of the ileum. L4 disease is further divided into upper disease proximal to the ligament of Treitz (L4a), upper disease distal to the ligament of Treitz and proximal to distal $1 / 3$ ileum (L4b), or both (L4ab) according to the Paris classification. ${ }^{10)}$ The disease's location should be defined by macroscopic rather than histological findings in normal-appearing mucosa.

\section{Clinical manifestations of UGl involvement of CD}

UGI symptoms precede distal GI symptoms in only $10 \%$ of patients with $\mathrm{CD}$, meaning that the L4 phenotype has a long asymptomatic phase. ${ }^{20)}$ Therefore, UGI involvement is underestimated and less commonly reported than lower GI involvement and usually occurs in patients with established ileal, large intestinal, or perianal CD. Nevertheless, the UGI involvement of CD should not be overlooked, as it can cause serious complications such as gastric outlet obstruction. ${ }^{21)}$ Clinical manifestations of UGI tract involvement of $C D$ vary by location.

The esophageal involvement of CD was initially described by Franklin and Taylor in $1950 .{ }^{22)}$ Most clinical manifestations of esophageal involvement are asymptomatic or mild with nonspecific UGI symptoms similar to gastroesophageal reflux disease; however, symptoms such as dysphagia, odynophagia, retrosternal pain, or severe heartburn may also occur. ${ }^{14)}$ In 2012, esophageal CD was hypothesized to progress through 3 phases. ${ }^{23)}$ The first phase involves inflammation, erosions, edema, and linear ulcers, followed by stenotic lesions with 
mucosal bridges (second phase). In the third stage, odynophagia, vomiting, and weight loss occur due to esophageal stricture.

Symptomatic gastroduodenal manifestations of $\mathrm{CD}$ occur in less than $4 \%$ of patients with CD. ${ }^{24)}$ Nonspecific symptoms such as nausea, dyspepsia, anorexia, and epigastric pain are the most frequent symptoms of gastroduodenal CD. Serious complications such as gastric outlet obstruction can cause early satiety, postprandial vomiting, weight loss, and rarely hematemesis. ${ }^{25)}$ In rare cases, biliary colic may occur secondary to the involvement of the ampulla of Vater ${ }^{26}$ or pancreatitis due to duodenal involvement. ${ }^{27,28)}$

If the lesion is confined to the jejunum or proximal ileum, abdominal colic is the main presenting symptom. Other GI manifestations such as diarrhea, weight loss, and fever are also present, and abnormal laboratory results, including anemia, hypoalbuminemia, iron deficiency, and folic acid deficiency, also occur in the majority of patients. ${ }^{29}$

\section{Endoscopic findings of UGI involvement of CD}

According to previous studies, the frequency of esophageal involvement in patients with $\mathrm{CD}$ is $0.2 \%-6.0 \%$, lower than that in the stomach and duoenum. ${ }^{30-32)}$ The macroscopic findings of esophageal lesions range from scattered erosions to ulcers that frequently have a longitudinal tendency (Fig. 1A) to those with a cobblestone appearance, and to more severe forms such as fistula and stricture. ${ }^{12,33-35)}$ However, these lesions are not specific to $\mathrm{CD}$, so eosinophilic esophagitis, viral and fungal infections, tuberculosis, vasculitis, and malignancies must be excluded. ${ }^{36)}$ Most esophageal lesions are located in the middle or distal esophagus or appear as diffuse inflammation on esophagogastroduodenoscopy (EGD). ${ }^{34)}$

Compared to esophageal involvement, gastric and duodenal involvement are relatively frequent findings in $\mathrm{CD} .{ }^{18,36}$ ) However, before the routine use of EGD to diagnose CD, gastroduodenal lesions were considered rare, occurring in an estimated $0.5 \%-4 \%$ of patients with $C D .{ }^{37)}$ At that time, most studies did not explain the specific endoscopic findings of proximal $\mathrm{CD}$, and it was believed that only the identification of noncaseating granulomas on a histopathological examination confirmed the diagnosis. ${ }^{38,39)}$ One of the most significant studies of the upper endoscopic findings of CD was reported in 1997.40) The authors reported that a bamboo joint-like appearance on EGD is a characteristic endoscopic finding in CD. Since then, many studies have attempted to identify the characteristic upper endoscopic findings of $\mathrm{CD}$ and the diagnostic value of EGD. ${ }^{41-44)}$

EGD with biopsy is the gold standard for the diagnosis of UGI CD. Endoscopic findings of gastroduodenal CD include ulceration, erosions, patchy erythematous mucosa, thickened folds, cobblestone appearance, bamboo joint-like appearance, fistula, and strictures. ${ }^{12,45)}$ Erosions often appear irregular and longitudinal, while ulcers can have various shapes such as aphthoid, linear, serpiginous, or stellate (Fig. 1B, C). ${ }^{37,45-47)}$

As mentioned above, longitudinal ulcers, fistulae, and strictures of the UGI tract are considered endoscopic findings specific to $\mathrm{CD}$ regardless of location. Although most macroscopic findings in EGD are nonspecific for $\mathrm{CD}$, some endoscopic findings may be characteristic when at specific locations in the UGI tract. The findings specific to UGI CD include aphthae, erosions, and ulcers in the esophagus; ${ }^{46)}$ a bamboo joint-like appearance in the stomach; $;^{40,41)}$ a notch-like appearance and nodular folds in the duodenum; ${ }^{42)}$ and nodular lymphoid hyperplasia, a villous pattern, and a cobblestone appearance in the small bowel. ${ }^{48)}$

The incidence of UGI involvement is 30\%-64\% when routine EGD is performed in patients with CD. ${ }^{15,49)}$ The EUROKIDS and the Hungarian IBD Registry reported that 35\%-67\% of pediatric patients with CD showed endoscopic abnormalities of the UGI tract and 9\%-24\% demonstrated characteristic macroscopic findings of CD. ${ }^{11,43)}$ This variation is largely associated with the lack of a standardized definition of UGI CD. ${ }^{44)}$

An Israeli group recently proposed a formalized scoring system for the UGI involvement of CD, the UGI-Simple Endoscopic Score for CD (UGI-SES-CD), which correlates with disease severity. ${ }^{50)}$ The UGI-SES-CD uses the same criteria as the SES-CD, a scoring system that evaluates the severity of the lower GI tract: ulcer size, ulcerated surface, affected surface, and narrowing to assess UGI CD severity. Disease severity is evaluated as the sum of the scores of the 4 regions (esophagus, stomach, antrum, and duodenum). As reported in that study, ongoing efforts are needed to enable a standardized assessment of UGI CD in the future.
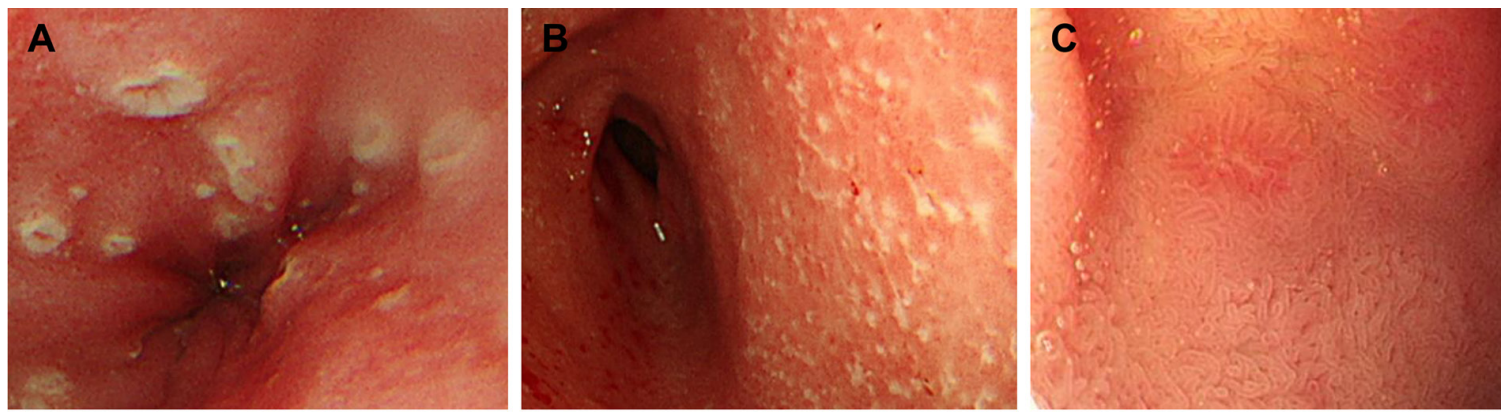

Fig. 1. Upper endoscopic findings of Crohn disease. (A) Esophageal ulcers showed a longitudinal tendency in Crohn disease. (B) Gastric ulcers and erosions in Crohn disease. (C) Duodenal ulcers in Crohn disease. 


\section{Pathologic findings of UGI involvement of CD}

Diagnosing CD by confirming inflammation of the UGI tract on a histological examination is challenging because its macroscopic and microscopic findings overlap with those of other diseases such as gastroesophageal reflux disease, immune-mediated disorders, and Helicobacter pylori infection. However, the histologic examination of the UGI tract is useful in diagnosing patients with IBD-unspecified or unclassified diagnoses, especially pediatric patients. ${ }^{44)}$

Esophageal involvement in patients with CD can be histologically seen in the form of active esophagitis, chronic esophagitis, and reflux esophagitis. ${ }^{51-53)}$ Inflammation is usually nonspecific, including erosions, ulcers, granulation tissue, or lymphoplasmacytic infiltrates. Lymphocytic esophagitis occurs in $12 \%-28 \%$ of pediatric CD patients but it is not a characteristic finding in adults. ${ }^{51,54)}$

Focally enhanced gastritis, chronic active and inactive gastritis, and chronic atrophic gastritis are nonspecific inflammatory patterns that are found in the stomach, ${ }^{38,45,55)}$ while duodenal inflammation is characterized by increased intraepithelial lymphocytes, crypt inflammation, and villous blunting. ${ }^{56}$ )

Focally enhanced gastritis, which consists of focal collections of histiocytes and lymphocytes surrounded by gastric foveola (Fig. 2A), is found in $\mathrm{CD}$ patients with a prevalence of 43\%-76\%.55,57,58) The reported sensitivity and specificity of focally enhanced gastritis for IBD are $35.7 \%$ and $96.6 \%$, respectively. ${ }^{59,60)}$ The presence of focally enhanced gastritis is highly associated with IBD in pediatric patients; however, it does not reliably distinguish between $\mathrm{CD}$ and ulcerative colitis.

H. pylori, one of the leading causes of gastritis, mimics the features of UGI involvement of CD on histologic examination. According to the Second Asia-Pacific Consensus Guidelines for $\mathrm{H}$. pylori infection, $H$. pylori infection should be excluded before the diagnosis of UGI CD can be made. ${ }^{61)}$ The H. pylori infection rate among CD patients is reportedly low. ${ }^{62-66)}$ Moreover, Park et al. ${ }^{67)}$ reported that $H$. pylori infections are relatively uncommon in Korean pediatric patients with CD.

Noncaseating granulomas are a specific histological finding of CD (Fig. 2B), but they are more difficult to detect in biopsy samples than in surgical specimens. ${ }^{68)}$ Granulomas can also be found in focal lesions or macroscopically in the normal mucosa. ${ }^{20)}$ Granulomas are most often identified in the gastric antrum (25\%), followed by the duodenal bulb (11\%) and the proximal or middle stomach (6\%). ${ }^{45,57)}$ Although the overall prevalence depends not only on biopsy number, depth, and quality, it also depends on the location of the affected UGI tract; thus, granulomas are found in $11 \%-40 \%$ of patients with CD. ${ }^{45}$ )

There is increasing interest in the endoscopic and histological differences by $\mathrm{CD}$ extent. Histological disease is reportedly more extensive than endoscopic disease at the time of $\mathrm{CD}$ diagnosis. ${ }^{69)}$ Although mucosal healing is a treatment target in the management of $\mathrm{CD},{ }^{70)}$ validated tools for the classification of $\mathrm{CD}$, such as the Paris classification, have no histological considerations. Therefore, the development of a classification system that divides disease extent using both endoscopic and histological criteria is necessary.

\section{Prognosis of UGI involvement of CD}

It is generally known that UGI involvement, that is, the L4 phenotype, in CD patients predicts a more severe disease phenotype requiring more aggressive treatment than those without UGI involvement. ${ }^{71)}$ L4 disease is associated with more extensive disease and extraintestinal manifestations. ${ }^{15)}$ However, the association between UGI involvement and a poor prognosis of CD remains controversial (Table 1 ).

Some studies argued that there is no significant relationship between $\mathrm{L} 4$ disease and CD prognosis. ${ }^{15,30,36)}$ Crocco et al. ${ }^{15)}$ reported no difference in prognosis between pediatric patients with and those without L4 disease. An analysis of Korean pediatric patients revealed no intergroup differences in complications requiring intestinal resection, ${ }^{30,72)}$ and the same result was obtained in a subgroup analysis of the presence or absence of jejunal involvement. ${ }^{30)}$ However, in both studies, patients with UGI involvement required more aggressive treatment than those without such involvement.

Other studies reported that UGI involvement is associated with poor outcomes such as relapse and the need for surgery. ${ }^{15,73-75)}$ Chow et al. ${ }^{76}$ revealed that a Chinese cohort of patients with
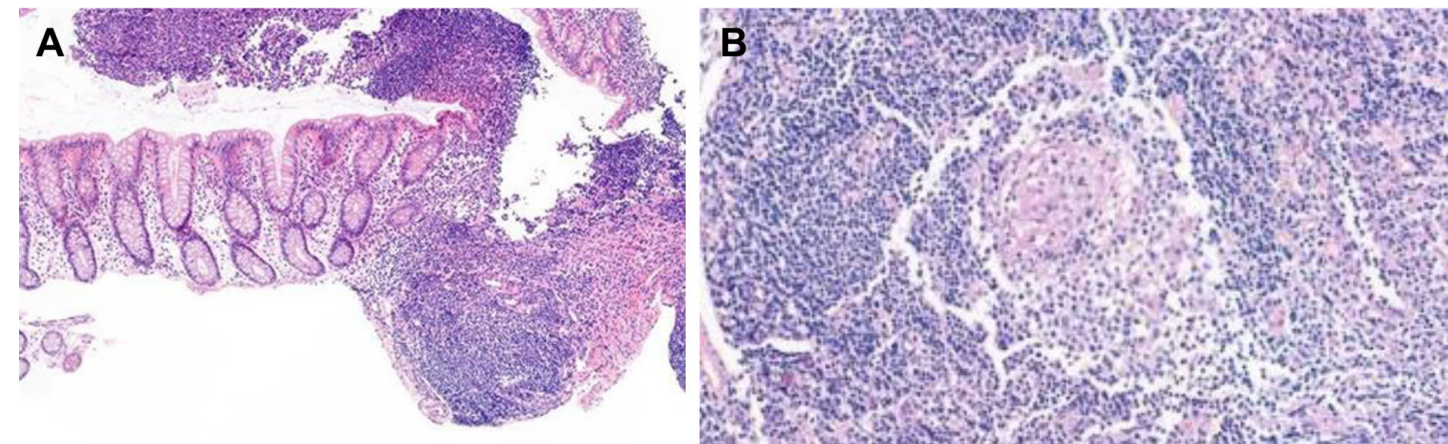

Fig. 2. Histopathologic findings of upper gastrointestinal tract of Crohn disease. (A) Gastric biopsy specimens showing small clusters of lymphocytes in the lamina propria indicating focally enhanced gastritis. (H\&E, $\times 4)(B)$ Duodenal biopsy specimens showing granuloma. $(H \& E, \times 64)$ 
Table 1. Previous studies of outcome of upper gastrointestinal involvement in Crohn disease

\begin{tabular}{|c|c|c|c|c|c|c|c|c|c|}
\hline Study & Ethnicity & $\begin{array}{l}\text { Pediatric } \\
\text { vs. } \\
\text { adult }\end{array}$ & Study design & $\begin{array}{l}\text { No. of } \\
\text { patients }\end{array}$ & $\begin{array}{c}\% \text { of UGI } \\
\text { involvement }\end{array}$ & Follow-up & Outcome surgery & Hospitalization & Etc. \\
\hline Sun et al. ${ }^{73)}$ & China & Adult & Retrospective & 246 & 32.5 & $>1 \mathrm{yr}$ & $\begin{array}{l}\text { Higher rates of ab- } \\
\text { dominal surgery in } \\
\text { L4 disease }\end{array}$ & $\begin{array}{l}\text { Similar rates between } \\
\text { L4 and non-L4 } \\
\text { disease }\end{array}$ & $\begin{array}{l}\text { Jejuno-ileum involve- } \\
\text { ment (L4b or L4ab) } \\
\text { was associated with } \\
\text { stricturing behavior. }\end{array}$ \\
\hline Greuter et al. ${ }^{36)}$ & Switzerland & Adult & Retrospective & 1,638 & 6.5 & $5 \mathrm{yr}$ & $\begin{array}{l}\text { L4 disease did not } \\
\text { show a worse out- } \\
\text { come compared } \\
\text { with non-L4 dis- } \\
\text { ease }\end{array}$ & $\mathrm{N} / \mathrm{M}$ & \\
\hline Lazarev et al. ${ }^{16)}$ & $\begin{array}{c}\text { USA, } \\
\text { Canada, } \\
\text { Puerto Rico }\end{array}$ & Adult & Retrospective & 2,105 & 16.4 & $\mathrm{~N} / \mathrm{M}$ & $\mathrm{N} / \mathrm{M}$ & $\mathrm{N} / \mathrm{M}$ & $\begin{array}{l}\text { Jejunal disease had } \\
\text { higher risk of B2 } \\
\text { phenotype and } \\
\text { abdominal surgery } \\
\text { than L4a or ileal } \\
\text { disease. }\end{array}$ \\
\hline Kim et al. ${ }^{75)}$ & Korea & Adult & Retrospective & 1,329 & 16.7 & $\mathrm{~N} / \mathrm{M}$ & $\begin{array}{l}\text { L4b disease showed } \\
\text { lower surgery-free } \\
\text { survival than non- } \\
\text { L4b disease. (58.4 } \\
\text { \% vs. } 67.7 \% \text { ) }\end{array}$ & $\mathrm{N} / \mathrm{M}$ & $\begin{array}{l}\text { Study included only } \\
\text { L4b type. }\end{array}$ \\
\hline Chow et al. ${ }^{76)}$ & China & Adult & Prospective & 132 & 22.7 & $\begin{array}{l}770 \\
\text { person- } \\
\text { years }\end{array}$ & $\begin{array}{l}\text { L4 disease showed } \\
\text { higher cumulative } \\
\text { probability of ma- } \\
\text { jor surgery than } \\
\text { non-L4 disease. }\end{array}$ & $\begin{array}{l}\text { L4 disease was as- } \\
\text { sociated with } \\
\text { longer hospitali- } \\
\text { zation than non- } \\
\text { L4 disease (HR, } \\
\text { 2.1) }\end{array}$ & \\
\hline Kim et al. ${ }^{21)}$ & Korea & Pediatric & Retrospective & 312 & 74.4 & $6.6 \mathrm{yr}$ & $\begin{array}{l}\text { L4 disease did not } \\
\text { show a worse out- } \\
\text { come compared } \\
\text { with non-L4 dis- } \\
\text { ease }\end{array}$ & $\mathrm{N} / \mathrm{M}$ & $\begin{array}{l}\text { Jejunal involvement } \\
\text { was not associated } \\
\text { with intestinal re- } \\
\text { section. }\end{array}$ \\
\hline Crocco et al. ${ }^{15)}$ & Italy & Pediatric & Prospective & 45 & 53.3 & $3 y r$ & $\begin{array}{l}\text { L4 disease did not } \\
\text { show a worse out- } \\
\text { come compared } \\
\text { with non-L4 dis- } \\
\text { ease }\end{array}$ & $\mathrm{N} / \mathrm{M}$ & $\begin{array}{l}\text { Patients with L4 dis- } \\
\text { ease required a more } \\
\text { aggressive treat- } \\
\text { ment. }\end{array}$ \\
\hline
\end{tabular}

\begin{tabular}{|c|c|c|c|c|c|c|}
\hline Kim et al. ${ }^{5)}$ & Korea & Pediatric Retrospective & 594 & 25.8 & $6.8 \mathrm{yr}$ & $\begin{array}{l}\text { L4 disease did not } \\
\text { show a worse out- } \\
\text { come compared } \\
\text { with non-L4 dis- } \\
\text { ease }\end{array}$ \\
\hline
\end{tabular}

$\mathrm{N} / \mathrm{M}$

UGI, upper gastrointestinal; N/M, not mentioned; L4, upper disease from esophagus to the proximal 2/3 of the ileum; L4a, upper disease proximal to ligament of Treitz; L4b, upper disease distal to ligament of Treitz and proximal to distal 1/3 ileum; L4ab, L4a and L4b; B2, stricturing phenotype; B3, penetrating phenotype; HR, hazard ratio.

UGI involvement had a more severe disease course, including strictures, fistulae, and the risk of longer hospitalization. Another study of a Chinese cohort reported that patients with L4 disease and UGI involvement showed higher rates of abdominal surgery (L4 disease vs. non-L4 disease: $41.3 \%$ vs. $11.4 \%$ ) but similar rates of hospitalization. ${ }^{73)}$

Other recent studies indicated that only L4-jejunal and L4proximal ileal phenotypes, rather than all UGI phenotypes, are associated with a higher risk of a poor prognosis. ${ }^{16,75,77,78)}$ Kim et al. ${ }^{75)}$ found that the surgery-free survival rate of patients with proximal small bowel involvement was lower than that of patients without such involvement (58.4\% vs. $67.7 \%)$. In addition, Lazarev et al. ${ }^{16}$ proposed that the L4 phenotype is heterogeneous in terms of disease phenotypes and outcomes. One study reported that patients with L4-jejunal disease had more strictures and fistulae requiring abdominal surgeries than those with L4-esophagogastroduodenal disease.

\section{Comparison of Korean and European patients}

Most studies to date reporting on UGI involvement in patients with $\mathrm{CD}$ are retrospective cohort studies. The prevalence of UGI tract involvement in adults is approximately $0.5 \%-16 \%$, and the diagnostic rate is increasing with the use of recently developed diagnostic techniques. ${ }^{15,16,73)}$ According to studies conducted in a European pediatric cohort, the prevalence of UGI involvement is $46.2 \%{ }^{49)}$ However, UGI involvement in Korean pediatric patients is reportedly $50.0 \%-74.4 \%$, higher than that of European patients. ${ }^{29,67)} \mathrm{Kim}$ et al. ${ }^{30)}$ reported that, 
compared to the EUROKIDS registry, Korean pediatric patients had significantly higher UGI involvement rates than European pediatric patients $(74.4 \%$ vs. $46.2 \%, P<0.001)$. Despite the use of the same strict definition of UGI tract involvement, the prevalence of UGI involvement differs between Korean and European pediatric patients.

One possible explanation for this difference is that race may play an important role in the expression of different phenotypes in pediatric $\mathrm{CD}$. Another explanation is the differences in the modalities of small bowel evaluation (L4b phenotype). The study of Korean pediatric patients was conducted from 2004 to 2019, and all patients underwent an accurate small bowel evaluation including MRE or capsule endoscopy. ${ }^{29)}$ However, since the EUROKIDS study was conducted from 2004 to 2009, less than half of the patients received advanced modalities for the small bowel evaluation. A total of $64 \%$ of patients were evaluated with small bowel follow-through, 38\% with MRE, 6\% with CT, and $5 \%$ with capsule endoscopy ${ }^{49}$ ) In fact, jejunal/ileal disease (L4b or L4ab) was identified in $48.1 \%$ of Korean pediatric patients compared to $24.1 \%$ of European pediatric patients. Further studies using the same definitions and evaluation methods are needed to enable accurate comparisons.

\section{Conclusion}

Pediatric CD involving the UGI tract has become increasingly recognized by the introduction of routine upper endoscopy with biopsy for all patients and the increased availability of accurate small bowel evaluations. Defining the disease phenotype helps clinicians assess disease severity and choose appropriate treatment strategies. Therefore, clinicians should be aware of the clinical, endoscopic, and histopathological findings of UGI involvement in CD. Debate persists about the association between UGI involvement in CD and disease prognosis. However, the lack of a standardized definition and absence of a validated tool for evaluating disease severity complicate the objective assessment of UGI involvement in CD. Therefore, future prospective studies are needed to provide further insight into the standardized assessment of UGI involvement in CD and determine long-term prognosis.

\section{Footnotes}

Conflicts of interest: No potential conflict of interest relevant to this article was reported.

ORCID:

Eun Sil Kim @ https://orcid.org/0000-0003-2012-9867

Mi Jin Kim @ https://orcid.org/0000-0002-4505-4083

\section{References}

1. Baumgart DC, Sandborn WJ. Crohn's disease. Lancet 2012;380:1590605.

2. Ghione S, Sarter H, Fumery M, Armengol-Debeir L, Savoye G, Ley D, et al. Dramatic increase in incidence of ulcerative colitis and Crohn's disease (1988-2011): a population-based study of French adolescents. Am J Gastroenterol 2018;113:265-72.

3. Ng SC, Shi HY, Hamidi N, Underwood FE, Tang W, Benchimol EI, et al. Worldwide incidence and prevalence of inflammatory bowel disease in the 21st century: a systematic review of population-based studies. Lancet 2017;390:2769-78.

4. Benchimol EI, Fortinsky KJ, Gozdyra P, Van den Heuvel M, Van Limbergen J, Griffiths AM. Epidemiology of pediatric inflammatory bowel disease: a systematic review of international trends. Inflamm Bowel Dis 201;17:423-39.

5. Kim BJ, Song SM, Kim KM, Lee YJ, Rhee KW, Jang JY, et al. Characteristics and trends in the incidence of inflammatory bowel disease in Korean children: a single-center experience. Dig Dis Sci 2010;55:1989-95.

6. van Rheenen PF, Aloi M, Assa A, Bronsky J, Escher JC, Fagerberg UL, et al. The medical management of paediatric Crohn's disease: an ECCOESPGHAN guideline update J Crohns Colitis 2020 Oct 7;jjaa161. https:// doi.org/10.1093/ecco-jcc/jjaa161. [Epub].

7. Cosnes J, Bourrier A, Nion-Larmurier I, Sokol H, Beaugerie L, Seksik P. Factors affecting outcomes in Crohn's disease over 15 years. Gut 2012;61:1140-5.

8. Zallot C, Peyrin-Biroulet L. Clinical risk factors for complicated disease: how reliable are they? Dig Dis 2012;30 Suppl 3:67-72.

9. Satsangi J, Silverberg MS, Vermeire S, Colombel JF. The Montreal classification of inflammatory bowel disease: controversies, consensus, and implications. Gut 2006;55:749-53.

10. Levine A, Griffiths A, Markowitz J, Wilson DC, Turner D, Russell RK, et al. Pediatric modification of the Montreal classification for inflammatory bowel disease: the Paris classification. Inflamm Bowel Dis 2011;17:131421.

11. Levine A, Koletzko S, Turner D, Escher JC, Cucchiara S, de Ridder L, et al. ESPGHAN revised porto criteria for the diagnosis of inflammatory bowel disease in children and adolescents. J Pediatr Gastroenterol Nutr 2014;58:795-806.

12. van Hogezand RA, Witte AM, Veenendaal RA, Wagtmans MJ, Lamers CB. Proximal Crohn's disease: review of the clinicopathologic features and therapy. Inflamm Bowel Dis 2001;7:328-37.

13. Horjus Talabur Horje CS, Meijer J, Rovers L, van Lochem EG, Groenen MJ, Wahab PJ. Prevalence of upper gastrointestinal lesions at primary diagnosis in adults with inflammatory bowel disease. Inflamm Bowel Dis 2016;22:1896-901.

14. Reynolds HL Jr, Stellato TA. Crohn's disease of the foregut. Surg Clin North Am 2001;81:117-35, viii.

15. Crocco S, Martelossi S, Giurici N, Villanacci V, Ventura A. Upper gastrointestinal involvement in paediatric onset Crohn's disease: prevalence and clinical implications. J Crohns Colitis 2012;6:51-5.

16. Lazarev M, Huang C, Bitton A, Cho JH, Duerr RH, McGovern DP, et al. Relationship between proximal Crohn's disease location and disease behavior and surgery: a cross-sectional study of the IBD Genetics Consortium. Am J Gastroenterol 2013;108:106-12.

17. Rowland M, Fleming P, Bourke B. Looking in the mouth for Crohn's disease. Inflamm Bowel Dis 2010;16:332-7.

18. Laube R, Liu K, Schifter M, Yang JL, Suen MK, Leong RW. Oral and upper gastrointestinal Crohn's disease. J Gastroenterol Hepatol 2018;33:35564.

19. Nugent FW, Roy MA. Duodenal Crohn's disease: an analysis of 89 cases. Am J Gastroenterol 1989;84:249-54.

20. Yamamoto T, Allan RN, Keighley MR. An audit of gastroduodenal Crohn disease: clinicopathologic features and management. Scand J Gastroenterol 1999;34:1019-24.

21. Kim ES, Park JH, Choe YH, Kim MJ. Pediatric Crohn's disease with severe morbidity manifested by gastric outlet obstruction: two cases report and 
review of the literature. Intest Res 2021;19:472-7.

22. Franklin RH, Taylor S. Nonspecific granulomatous (regional) esophagitis. J Thorac Surg 1950;19:292-7.

23. Wang W, Ni Y, Ke C, Cheng Q, Lu Q, Li X. Isolated Crohn's disease of the esophagus with esophago-mediastinal fistula formation. World J Surg Oncol 2012;10:208.

24. Wagtmans MJ, Verspaget HW, Lamers CB, van Hogezand RA. Clinical aspects of Crohn's disease of the upper gastrointestinal tract: a comparison with distal Crohn's disease. Am J Gastroenterol 1997;92:1467-71.

25. Mottet C, Juillerat P, Pittet V, Gonvers JJ, Michetti P, Vader JP, et al. Upper gastrointestinal Crohn's disease. Digestion 2007;76:136-40.

26. Cooper MB, Winawer SJ. Gastroduodenal Crohn's disease presenting as biliary colic. Am J Gastroenterol 1975;63:481-5.

27. Ramos LR, Sachar DB, DiMaio CJ, Colombel JF, Torres J. Inflammatory Bowel disease and pancreatitis: a review. J Crohns Colitis 2016;10:95104.

28. Eisner TD, Goldman IS, McKinley MJ. Crohn's disease and pancreatitis. Am J Gastroenterol 1993;88:583-6.

29. Cooke WT, Swan CH. Diffuse jejuno-ileitis of Crohn's disease. Q J Med 1974;43:583-601.

30. Kim ES, Kwon Y, Choe YH, Kim MJ. Upper gastrointestinal tract involvement is more prevalent in Korean patients with pediatric Crohn's disease than in European patients. Sci Rep 2020;10:19032.

31. Kamboj AK, Kane SV, Leggett CL. Crohn's disease of the esophagus. Clin Gastroenterol Hepatol 2020 Oct 17;S1542-3565(20)31445-2. https:// doi.org/10.1016/j.cgh.2020.10.032. [Epub].

32. Decker GA, Loftus EV Jr, Pasha TM, Tremaine WJ, Sandborn WJ. Crohn's disease of the esophagus: clinical features and outcomes. Inflamm Bowel Dis 2001;7:113-9.

33. Naranjo-Rodríguez A, Solórzano-Peck G, López-Rubio F, CalañasContinente A, Gálvez-Calderón C, González-Galilea A, et al. Isolated oesophageal involvement of Crohn's disease. Eur J Gastroenterol Hepatol 2003;15:1123-6.

34. De Felice KM, Katzka DA, Raffals LE. Crohn's disease of the esophagus: clinical features and treatment outcomes in the biologic era. Inflamm Bowel Dis 2015;21:2106-13.

35. Wespi SP, Frei R, Sulz MC. A very rare cause of a relapsing paraoesophageal abscess. Case Rep Gastroenterol 2016;10:132-8.

36. Greuter T, Piller A, Fournier N, Safroneeva E, Straumann A, Biedermann L, et al. Upper gastrointestinal tract involvement in Crohn's disease: frequency, risk factors, and disease course. J Crohns Colitis 2018;12:1399-409.

37. Rutgeerts P, Onette E, Vantrappen G, Geboes K, Broeckaert L, Talloen L. Crohn's disease of the stomach and duodenum: A clinical study with emphasis on the value of endoscopy and endoscopic biopsies. Endoscopy 1980;12:288-94.

38. Schmitz-Moormann P, Malchow H, Pittner PM. Endoscopic and bioptic study of the upper gastrointestinal tract in Crohn's disease patients. Pathol Res Pract 1985;179:377-87.

39. Danzi JT, Farmer RG, Sullivan BH Jr, Rankin GB. Endoscopic features of gastroduodenal Crohn's disease. Gastroenterology 1976;70:9-13.

40. Yokota K, Saito Y, Einami K, Ayabe T, Shibata Y, Tanabe H, et al. A bamboo joint-like appearance of the gastric body and cardia: possible association with Crohn's disease. Gastrointest Endosc 1997;46:268-72.

41. Fujiya M, Sakatani A, Dokoshi T, Tanaka K, Ando K, Ueno N, et al. A bamboo joint-like appearance is a characteristic finding in the upper gastrointestinal tract of Crohn's disease patients: a case-control study. Medicine (Baltimore) 2015;94:e1500.

42. Hokama A, Nakamura M, Ihama Y, Chinen H, Kishimoto K, Kinjo F, et al. Notched sign and bamboo-joint-like appearance in duodenal Crohn's disease. Endoscopy 2008;40 Suppl 2:E151.

43. Kovacs M, Muller KE, Arato A, Lakatos PL, Kovacs JB, Varkonyi A, et al. Diagnostic yield of upper endoscopy in paediatric patients with Crohn's disease and ulcerative colitis. Subanalysis of the HUPIR registry. J Crohns Colitis 2012;6:86-94.

44. Turner D, Griffiths AM. Esophageal, gastric, and duodenal manifestations of IBD and the role of upper endoscopy in IBD diagnosis. Curr
Gastroenterol Rep 2007;9:475-8.

45. Sakuraba A, Iwao Y, Matsuoka K, Naganuma M, Ogata H, Kanai T, et al. Endoscopic and pathologic changes of the upper gastrointestinal tract in Crohn's disease. Biomed Res Int 2014;2014:610767.

46. Lenaerts C, Roy CC, Vaillancourt M, Weber AM, Morin CL, Seidman E. High incidence of upper gastrointestinal tract involvement in children with Crohn disease. Pediatrics 1989;83:777-81.

47. Cameron DJ. Upper and lower gastrointestinal endoscopy in children and adolescents with Crohn's disease: a prospective study. J Gastroenterol Hepatol 1991;6:355-8.

48. Carbo AI, Reddy T, Gates T, Vesa T, Thomas J, Gonzalez E. The most characteristic lesions and radiologic signs of Crohn disease of the small bowel: air enteroclysis, MDCT, endoscopy, and pathology. Abdom Imaging 2014;39:215-34.

49. de Bie CI, Paerregaard A, Kolacek S, Ruemmele FM, Koletzko S, Fell JM, et al. Disease phenotype at diagnosis in pediatric Crohn's disease: 5 -year analyses of the EUROKIDS Registry. Inflamm Bowel Dis 2013;19:37885 .

50. Ledder O, Church P, Cytter-Kuint R, Martinez-Leon M, Sladek M, Coppenrath E, et al. A Simple Endoscopic Score Modified for the Upper Gastrointestinal Tract in Crohn's Disease [UGI-SES-CD]: a report from the ImageKids study. J Crohns Colitis 2018;12:1073-8.

51. Ebach DR, Vanderheyden AD, Ellison JM, Jensen CS. Lymphocytic esophagitis: a possible manifestation of pediatric upper gastrointestinal Crohn's disease. Inflamm Bowel Dis 2011;17:45-9.

52. Castellaneta SP, Afzal NA, Greenberg M, Deere H, Davies S, Murch SH, et al. Diagnostic role of upper gastrointestinal endoscopy in pediatric inflammatory bowel disease. J Pediatr Gastroenterol Nutr 2004;39:25761.

53. Hummel TZ, ten Kate FJ, Reitsma JB, Benninga MA, Kindermann A. Additional value of upper GI tract endoscopy in the diagnostic assessment of childhood IBD. J Pediatr Gastroenterol Nutr 2012;54:753-7.

54. Sutton LM, Heintz DD, Patel AS, Weinberg AG. Lymphocytic esophagitis in children. Inflamm Bowel Dis 2014;20:1324-8.

55. Oberhuber G, Püspök A, Oesterreicher C, Novacek G, Zauner C, Burghuber M, et al. Focally enhanced gastritis: a frequent type of gastritis in patients with Crohn's disease. Gastroenterology 1997;112:698-706.

56. Hardee S, Alper A, Pashankar DS, Morotti RA. Histopathology of duodenal mucosal lesions in pediatric patients with inflammatory bowel disease: statistical analysis to identify distinctive features. Pediatr Dev Pathol 201;17:450-4.

57. Oberhuber G, Hirsch M, Stolte M. High incidence of upper gastrointestinal tract involvement in Crohn's disease. Virchows Arch 1998;432:4952.

58. Parente F, Cucino C, Bollani S, Imbesi V, Maconi G, Bonetto S, et al. Focal gastric inflammatory infiltrates in inflammatory bowel diseases: prevalence, immunohistochemical characteristics, and diagnostic role. Am J Gastroenterol 2000;95:705-11.

59. Roka K, Roma E, Stefanaki K, Panayotou I, Kopsidas G, Chouliaras G. The value of focally enhanced gastritis in the diagnosis of pediatric inflammatory bowel diseases. J Crohns Colitis 2013;7:797-802.

60. McHugh JB, Gopal P, Greenson JK. The clinical significance of focally enhanced gastritis in children. Am J Surg Pathol 2013;37:295-9.

61. Fock KM, Katelaris P, Sugano K, Ang TL, Hunt R, Talley NJ, et al. Second Asia-Pacific Consensus Guidelines for Helicobacter pylori infection. J Gastroenterol Hepatol. 2009; 24:1587-600.

62. Sonnenberg A, Genta RM. Low prevalence of Helicobacter pylori infection among patients with inflammatory bowel disease. Aliment Pharmacol Ther 2012;35:469-76.

63. Wu XW, Ji HZ, Yang MF, Wu L, Wang FY. Helicobacter pylori infection and inflammatory bowel disease in Asians: a meta-analysis. World J Gastroenterol 2015;21:4750-6.

64. Song MJ, Park DI, Hwang SJ, Kim ER, Kim YH, Jang BI, et al. The prevalence of Helicobacter pylori infection in Korean patients with inflammatory bowel disease, a multicenter study. Korean J Gastroenterol 2009;53:341-7. (Korean).

65. Bartels LE, Jepsen P, Christensen LA, Gerdes LU, Vilstrup H, Dahlerup 
JF. Diagnosis of Helicobacter Pylori Infection is Associated with Lower Prevalence and Subsequent Incidence of Crohn's Disease. J Crohns Colitis 2016;10:443-8.

66. Wagtmans MJ, Witte AM, Taylor DR, Biemond I, Veenendaal RA, Verspaget HW, et al. Low seroprevalence of Helicobacter pylori antibodies in historical sera of patients with Crohn's disease. Scand J Gastroenterol 1997;32:712-8.

67. Park JH, Nam HN, Lee JH, Hong J, Yi DY, Ryoo E, et al. Characteristics of upper gastrointestinal tract involvement in Korean Pediatric Crohn's disease: a multicenter study. Pediatr Gastroenterol Hepatol Nutr 2017; 20:227-35.

68. Birimberg-Schwartz L, Zucker DM, Akriv A, Cucchiara S, Cameron FL, Wilson DC, et al. Development and validation of diagnostic criteria for IBD subtypes including IBD-unclassified in children: a multicentre study from the pediatric IBD Porto Group of ESPGHAN. J Crohns Colitis 2017;11:1078-84.

69. Ashton JJ, Coelho T, Ennis S, Vadgama B, Batra A, Afzal NA, et al. Endoscopic versus histological disease extent at presentation of paediatric inflammatory bowel disease. J Pediatr Gastroenterol Nutr 2016;62:24651.

70. Colombel JF, D'haens G, Lee WJ, Petersson J, Panaccione R. Outcomes and strategies to support a treat-to-target approach in inflammatory bowel disease: a systematic review. J Crohns Colitis 2020;14:254-66.

71. Cosnes J, Cattan S, Blain A, Beaugerie L, Carbonnel F, Parc R, et al. Longterm evolution of disease behavior of Crohn's disease. Inflamm Bowel Dis 2002;8:244-50.

72. Kim HJ, Oh SH, Kim DY, Lee HS, Park SH, Yang SK, et al. Clinical characteristics and long-term outcomes of paediatric Crohn's disease: a single-centre experience. J Crohns Colitis 2017;11:157-64.
73. Sun XW, Wei J, Yang Z, Jin XX, Wan HJ, Yuan BS, et al. Clinical features and prognosis of Crohn's disease with upper gastrointestinal tract phenotype in Chinese patients. Dig Dis Sci 2019;64:3291-9.

74. Moon JS, Lee JL, Yu CS, Lim SB, Park IJ, Yoon YS, et al. Clinical characteristics and postoperative outcomes of patients presenting with upper gastrointestinal tract Crohn disease. Ann Coloproctol 2020;36:243-8.

75. Kim OZ, Han DS, Park CH, Eun CS, Kim YS, Kim YH, et al. The clinical characteristics and prognosis of Crohn's disease in Korean patients showing proximal small bowel involvement: results from the CONNECT study. Gut Liver 2018;12:67-72.

76. Chow DK, Sung JJ, Wu JC, Tsoi KK, Leong RW, Chan FK. Upper gastrointestinal tract phenotype of Crohn's disease is associated with early surgery and further hospitalization. Inflamm Bowel Dis 2009;15:551-7.

77. Park SK, Yang SK, Park SH, Park SH, Kim JW, Yang DH, et al. Longterm prognosis of the jejunal involvement of Crohn's disease. J Clin Gastroenterol 2013;47:400-8.

78. Mao R, Tang RH, Qiu Y, Chen BL, Guo J, Zhang SH, et al. Different clinical outcomes in Crohn's disease patients with esophagogastroduodenal, jejunal, and proximal ileal disease involvement: is L4 truly a single phenotype? Therap Adv Gastroenterol 2018;11:1756284818777938.

How to cite this article: Kim ES, KimMJ. Upper gastrointestinal tract involvement of Crohn disease: clinical implications in children and adolescents. Clin Exp Pediatr 2022;65:21-8. https://doi.org/10.3345/cep.2021.00661 